\title{
Underestimated responses of Walker circulation to ENSO-related SST anomaly in atmospheric and coupled models
}

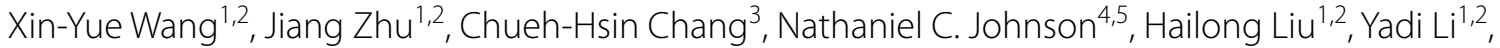 \\ Chentao Song ${ }^{1,2}$, Meijiao Xin ${ }^{1,2}$, Yi Zhou $^{1,2}$ and Xichen $\mathrm{Li}^{1,6^{*}}$
}

\begin{abstract}
The Pacific Walker circulation (WC) is a major component of the global climate system. It connects the Pacific sea surface temperature (SST) variability to the climate variabilities from the other ocean basins to the mid- and high latitudes. Previous studies indicated that the ENSO-related atmospheric feedback, in particular, the surface wind response is largely underestimated in AMIP and CMIP models. In this study, we further investigate the responses in the WC stream function and the sea level pressure (SLP) to the ENSO-related SST variability by comparing the responses in 45 AMIP and 63 CMIP models and six reanalysis datasets. We reveal a diversity in the performances of simulated SLP and WC between different models. While the SLP responses to the EI Niño-related SST variability are well simulated in most of the atmospheric and coupled models, the WC stream function responses are largely underestimated in most of these models. The WC responses in the AMIP5/6 models capture $75 \%$ of those in the reanalysis, whereas the CMIP5/6 models capture $58 \%$ of the responses. Further analysis indicates that these underestimated circulation responses could be partially attributed to the biases in the precipitation scheme in both the atmospheric and coupled models, as well as the biases in the simulated ENSO-related SST patterns in the coupled models. One should pay special attention to these biases when studying the WC or the tropical atmosphere-ocean interactions using numerical models.
\end{abstract}

Keywords: Pacific Walker circulation, ENSO, AMIP5/6 and CMIP5/6 models, Atmosphere-ocean interaction, Model bias

\section{Introduction}

The Pacific Walker circulation (WC) is a large-scale zonal overturning circulation in the atmosphere, which is characterized by rising motion and deep convection over the equatorial western Pacific and Maritime Continent, and strong easterly surface winds over the equatorial Pacific (Bjerknes 1969; Lau and Yang 2003). On interannual time scales, variations in the WC are tightly connected to El Niño-Southern Oscillation (ENSO, Rasmusson and

\footnotetext{
${ }^{*}$ Correspondence: lixichen@mail.iap.ac.cn

${ }^{1}$ Institute of Atmospheric Physics, Chinese Academy of Sciences, Beijing, China

Full list of author information is available at the end of the article
}

Carpenter 1982; Tanaka et al. 2004) and impacts global climate through atmospheric teleconnections (Lau and Yang 2003; Power et al. 1999). During an El Niño or La Niña event, anomalous SST in equatorial Pacific leads to changes of the WC, whereas the WC strengthens or weakens the SST gradient in turn (Wang et al. 2016). The so-called Bjerknes feedback is the most fundamental mechanism to maintain tropical Pacific air-sea interaction.

The WC is the essential medium between the atmosphere and the ocean (Lau and Yang 2003). Interaction between WC and SST determines regional-to-global climate variability (Li et al. 2016; Wang et al. 2012). The capability of present climate models to simulate these 
interactions and feedbacks is a long-lasting research topic that directly affects the reliability of climate predictions and projections. In particular, the Coupled Model Intercomparison Project and the Atmospheric Model Intercomparison Project phase 5 and 6 (CMIP5/6 and AMIP5/6; Gates et al. 1999; Taylor et al. 2012) multimodel simulation results may help us to examine the skill of these models in simulating the feedbacks between tropical ocean and atmosphere.

Recently, a series of studies suggested that the simulated zonal SST gradient over the equatorial Pacific, the zonal surface wind feedback, the variability of east-west sea level pressure gradient, and the negative shortwave cloud feedback, etc., are all underestimated by most of the CMIP models compared with observations (Bayr et al. 2020; Bellenger et al. 2014; Davey et al. 2002; DiNezio et al. 2013; Kociuba and Power 2015; Mechoso et al. 1995; Stocker et al. 2013). In particular, the wind feedback is underestimated in both AMIP5 and CMIP5 models (Bayr et al. 2020). The weaker zonal surface wind feedback and surface-heat flux feedback are associated with deep convection over the equatorial central Pacific and further involve SST bias over the equatorial Pacific (Bayr et al. 2020). Meanwhile, the underestimated zonal surface wind feedback in CMIP models reduces the biases in nonlinear dynamical heating along the equatorial Pacific thermocline, declining modeled ENSO asymmetry (Hayashi et al. 2020). In addition, the coupled models also suffer from the double Intertropical Convergence Zone (ITCZ) problem (Zhang et al. 2015). A recent study indicated that the metrics of ENSO processes are not improved from CMIP5 to CMIP6 (Planton et al. 2020), consistent with Hayashi et al. (2020). The above biases may potentially influence the interactions between the WC and the tropical Pacific SST variability. Many studies have quantified the ENSO-related atmospheric feedback biases in AMIP and CMIP models (Bayr et al. 2020; Hayashi et al. 2020; Planton et al. 2020). However, the responses and the feedbacks of SLP and zonal mass stream function to the ENSO-related SST forcing in the state-of-the-art atmosphere and coupled models have not been well investigated. SLP and zonal mass stream function are important measures of the $\mathrm{WC}$, and the change of these two variables are also key components of ENSO feedback.

Considering that ENSO events are typically phaselocked, the strongest SST and circulation anomalies over the central-eastern equatorial Pacific typically appears in boreal winter (Rasmusson and Carpenter 1982; Wang et al. 2016). In this study, we attempt to revisit the ENSO feedback biases in AMIP and CMIP simulations in terms of the WC that was defined by the SLP and mass stream function, and quantify the responses of the WC to ENSO-related SST variability in the boreal winter (December, January and February; DJF) in both AMIP and CMIP models by comparing with six independent reanalysis datasets. In previous studies, surface wind, sea level pressure and mass stream function are usually used to examine the change of Pacific Walker circulation in observations and models (e.g., Kociuba and Power 2015; Vecchi and Soden 2007; Ma et al. 2016; Yu and Zwiers 2010). And surface wind responses to ENSO SST anomalies in climate models are underestimated (Bayr et al. 2020; Hayashi et al. 2020). However, the biases in reproduced responses of sea level pressure and mass stream function to ENSO-related SST variability in the state-of-the-art climate models remain unclear and are worth exploring. By statistical analysis, we found that models show a diversity in reproducing the responses to ENSO-related SST. The responses of sea level pressure simulated by AMIP5/6 and CMIP5/ 6 models are reasonable. However, the responses of mass stream function are significantly underestimated in AMIP and CMIP models compared to that in reanalyses. Further, we show evidences that, the biases in the precipitation responses in both the atmospheric and coupled models, as well as the biases in the simulated ENSO-related SST patterns in the coupled models, are important contributors to the underestimation.

\section{Data and methods}

In this study, we represent the ENSO-related Pacific SST forcing with the Niño3.4 index (spatial-mean SST anomalies over the area $\left.5^{\circ} \mathrm{S}-5^{\circ} \mathrm{N}, 170^{\circ} \mathrm{W}-120^{\circ} \mathrm{W}\right)$, which is a common metric for measuring the intensity of ENSO. Many studies considered the zonal gradient of Sea Level Pressure (SLP) in the equatorial Pacific as an important parameter characterizing the intensity of the $\mathrm{WC}$, defined by the Southern Oscillation Index (SOI, the difference of the spatial-mean SLP between the west Pacific $\left(5^{\circ} \mathrm{S}-5^{\circ} \mathrm{N}, 160^{\circ}-80^{\circ} \mathrm{W}\right)$ and the east Pacific $\left(5^{\circ} \mathrm{S}-5^{\circ}\right.$ $\mathrm{N}, 80^{\circ} \mathrm{E}-160^{\circ} \mathrm{E}$ ); Kociuba and Power 2015; Vecchi and Soden 2007). In addition, zonal mass stream function is used to depict the structure of the WC, as defined in $\mathrm{Yu}$ and Zwiers (2010) and Yu et al. (2012):

$$
\Psi=\frac{a \Delta \varphi}{g} \int_{0}^{\mathrm{P}} u_{D} d p
$$

where $\Psi$ is the zonal mass stream function, $a$ is the Earth radius, $\Delta \varphi$ is the width of the $5^{\circ} \mathrm{S}-5^{\circ} \mathrm{N}$ band along the equator in radians, $g$ is the gravitational acceleration, $u_{D}$ is the divergent component of the zonal wind, and $\mathrm{p}$ is the pressure. The results of zonal mass stream function above $100 \mathrm{hPa}$ are not shown in this study, because the stream function is nearly zero above $100 \mathrm{hPa}$. The maximum of 
vertically averaged zonal mass stream function over the Pacific $\left(100^{\circ} \mathrm{E}-120^{\circ} \mathrm{W}\right)$ locate around the center of the cell, which is used to quantify the strength of the WC in this study. On the other hand, tropical precipitation reflects the change of deep convection associated with the WC. The west Pacific warm pool region $\left(10^{\circ} \mathrm{S}-10^{\circ} \mathrm{N}\right.$, $\left.95^{\circ} \mathrm{E}-145^{\circ} \mathrm{E}\right)$ and the equatorial central-eastern Pacific $\left(5^{\circ} \mathrm{S}-5^{\circ} \mathrm{N}, 165^{\circ} \mathrm{E}-135^{\circ} \mathrm{W}\right)$ are used to quantify the precipitation responses. As a result, we used monthly SST, SLP, zonal mass stream function, and precipitation to examine the responses of the $\mathrm{WC}$ in observations, reanalysis, and AMIP5/6 and CMIP5/6 models.

The responses of the above variables in the r1ilp1 ensemble member from AMIP5/6 runs and CMIP5/6 historical runs are explored. We analyze the performance in 45 CMIP5 models, 18 CMIP6 models, 29 AMIP5 models and 16 AMIP6 models. Considering that the CanESM5 models in CMIP6 include numerical bugs in the r1ilp1 realization (https://gmd.copernicus.org/preprints/ gmd-2019-177/gmd-2019-177-AC3-supplement.pdf), we use the r1i1p2 realization to evaluate the responses. The names of the models are listed in Additional file 1: Table S1. Six reanalysis datasets are used as references: (1) Twentieth Century Reanalysis (20CR; Compo et al. 2011); (2) Climate Forecast System Reanalysis (CFSR; Saha et al. 2010); (3) the ERA-Interim reanalysis data from the European Centre for Medium-Range Weather Forecasts (ECMWF; Dee et al. 2011); (4) the Japanese 55-year Reanalysis (JRA55; Kobayashi et al. 2015); (5) Modern-Era Retrospective analysis for Research and Applications (MERRA; Rienecker et al. 2011); (6) NCEPDOE Reanalysis 2 (NCEP2; Kanamitsu et al. 2002). The observed SST data is from Extended Reconstructed Sea Surface Temperature Version5 (ERSSTv5; Huang et al. 2017). The precipitation data from the Global Precipitation Climatology Project (GPCP; Huffman et al. 2009) is used to investigate and quantify the observed precipitation responses. Because reanalysis datasets start from 1979, whereas CMIP model datasets end in 2005, we analyze the responses of WC during the boreal winter (DJF) from 1979 to 2005.

In this study, the responses of the tropical atmospheric circulation to ENSO SST variability are calculated by regressing the SOI and the stream function onto the Niño3.4 SST index. The confidence interval is calculated using Student's $t$ test. Linear trends from each time series are removed before regression analysis. The regression coefficients are thus considered as the magnitudes of the WC responses to SST change. We adopt the widely used Empirical Orthogonal Function (EOF, Zhang 2016; Zhang et al. 2010) to compare the dominant modes of ENSO-related SST in observations and CMIP5/6 models, in order to examine the possible causes of the biases in couple models. We not only focus on the responses in individual datasets, but also analyzed the responses in all reanalyses (or models) as an ensemble. The ensemble is formed by concatenating the anomalous time series of all individual datasets (reanalysis or model).

\section{Results}

The zonal equatorial Pacific SLP gradient is an important signature of the WC's strength in observations and models, which has been broadly used in previous studies to quantify the changes and variability of the WC (DiNezio et al. 2013; Kociuba and Power 2015). Therefore, we first calculate the SLP responses to the Niño3.4 SST anomalies in reanalyses, AMIP5/6 and CMIP5/6 models (Fig. 1a-e). An El Niño event is usually associated with a weakened WC and thus a weakened SOI. We quantify the responses of SOI by regressing it against the Niño3.4 SST index using different datasets and show the corresponding box-whisker plots. Quantitative analysis (Fig. 1f) shows that the relatively smaller magnitudes appear in CMIP6 models, explaining $81 \%$ variation of reanalysis. Results (Fig. 1f) indicate that the responses of SOI in AMIP5/6 and CMIP $5 / 6$ capture more than $\sim 81 \%$ of that in reanalyses. The boxplot (Fig. 1g) also suggests that most models reproduce the responses of SLP reasonably well. The underestimation in CMIP6 is evident compared to other models. It is possible that the increase of ENSO SSTA amplitude from CMIP5 to CMIP6 is an important contributor to the underestimation. Less numbers of CMIP6 models may have a potential impact of underestimation. The responses of SLP to the Pacific SST anomalies in models capture the main features in general. However, the tropical atmospheric circulation could not be directly measured by the SLP gradient. We thus estimate the responses of the zonal mass stream function over the equatorial Pacific to the Niño3.4 SST anomalies in different datasets. The stream function directly represents the vertical structure of the WC (Ma and Zhou 2016). The central-east equatorial Pacific SST warming associated with El Niño events induces a weakened WC over the central-western Pacific in all datasets (purple colors in Fig. 2a-e), but the magnitudes of these responses in reanalyses, AMIP5/6 and CMIP5/6 are substantially different. The amplitudes of the responses (determined as the maximum value of stream function regressed onto the Niño3.4 SST) in the AMIP5/6 and CMIP5/6 models are approximately $75 \%$ (the mean of AMIP5 and AMIP6) and 58\% (the mean of CMIP5 and CMIP6) of that in the reanalysis datasets, respectively (Fig. $2 \mathrm{f}, \mathrm{g}$ ). These results indicate that the responses of the WC to the ENSOrelated SST variability may be significantly underestimated in the atmospheric and coupled models, especially the latter. 


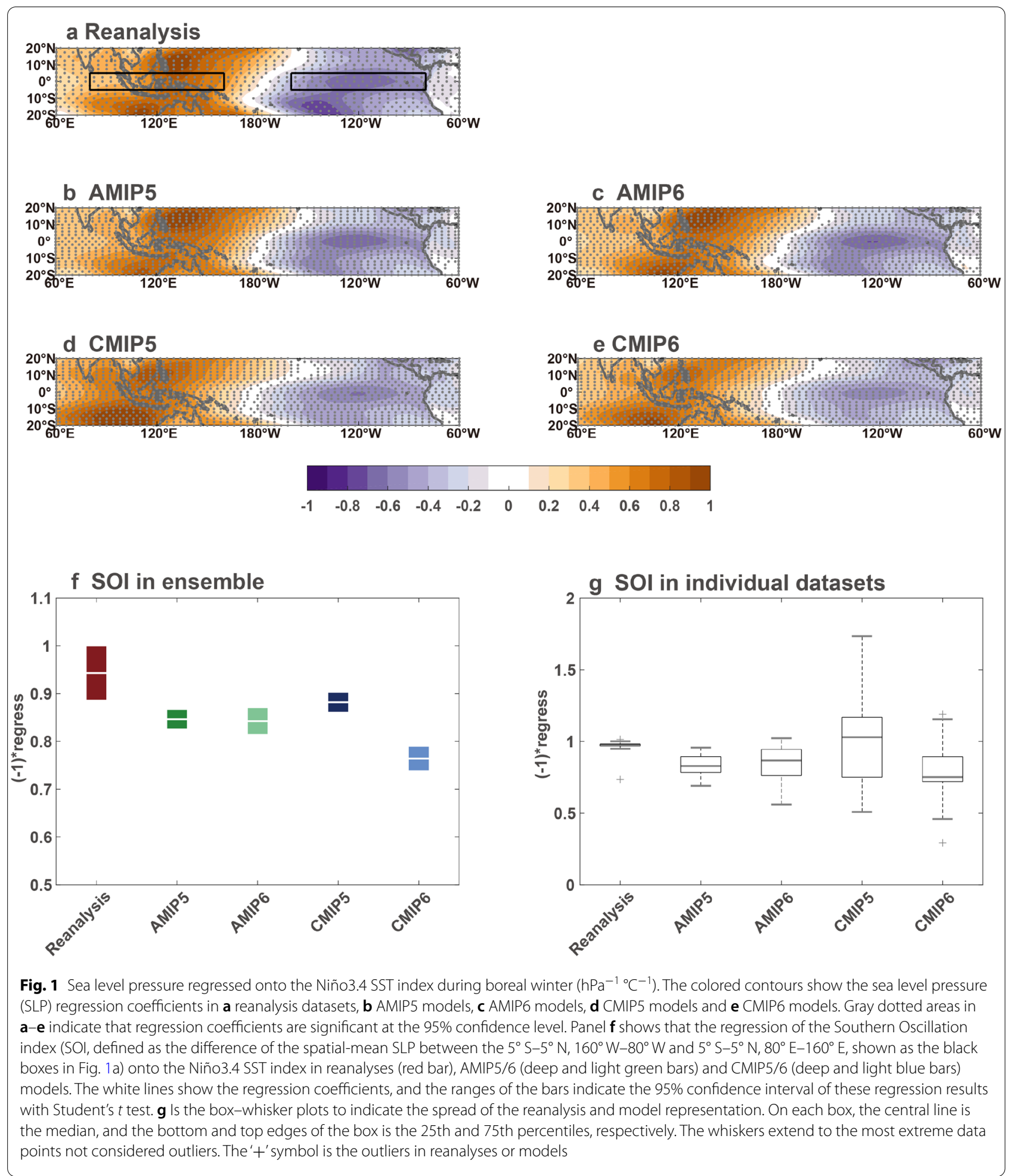

Figures 1 and 2 show the circulation responses in multi-reanalysis and model ensembles, we further examine the responses of WC to Niño3.4 SST in each individual reanalysis and AMIP/CMIP model. The regression results of the SLP in each AMIP and CMIP model are shown in Additional file 1: Figs. S1, S2, while the regression results of the stream function are shown in Additional file 1: Figs. S3, S4. Most of AMIP5/6 (Additional 
file 1: Fig. S1) and CMIP5/6 (Additional file 1: Fig. S2) models reasonably reproduce the SLP patterns compared to reanalysis datasets (Fig. S1). However, the simulated zonal mass stream function responses are weaker than those of the SLP. In AMIP5/6, only one-third of the models capture the main feature and the amplitude of the stream function responses shown in the reanalyses, while the responses in the other models are weaker (Additional file 1: Fig. S3). The simulation results in CMIP5/6 models are even worse, with the responses of zonal mass stream function in most of the CMIP5/6 models obviously underestimated (Additional file 1: Fig. S4) compared with those in the reanalyses (Additional file 1: Fig. S3). The figure of Taylor diagram shows model performance of the atmospheric responses (Additional file 1: Fig. S5), which supports our conclusion. The spatial pattern correlation coefficients of SLP between models and reanalysis-ensemble is larger than 0.8. However, the zonal mass stream function responses in most CMIP models are worse than that in AMIP models.

We further quantify the SLP (Fig. 3) and stream function (Fig. 4) responses in each individual reanalysis dataset and AMIP/CMIP model. Bars in Figs. 3, 4 represent the magnitude of the responses of each reanalysis dataset (red bar), AMIP5/6 (deep/light green) and CMIP5/6 (deep/light blue) model, with the red lines showing the responses in the multi-reanalysis data, and green and blue lines showing those in the AMIP and CMIP models, respectively. Gray shadings indicate the ranges of \pm 1 standard deviation of the responses in the reanalysis datasets. The SOI responses in most of AMIP5/6 models are within the gray shaded area (Fig. 3a), indicating that most of the AMIP models can well simulate the SOI responses to the ENSO-related SST variability. It is interesting that the performance of some of the AMIP6 models (light green bars in Fig. 3a, such as GISS-E2-1-G and NESM3) is even worse than those of the AMIP5 models (dark green bars in Fig. 3a), which should be noted by the users and developers of these models. The SOI responses in CMIP5/6 models show a stronger diversity, with onethird of coupled models showing stronger responses than those the reanalyses (Fig. 3b). The responses of $~ 25 \%$ of models (16 out of 63 ) are located within the \pm 1 standard deviation shading area of the reanalyses, and $42 \%$ of models (26 out of 63 ) exhibit relative weaker responses. Overall, most of the atmospheric and coupled models can reasonably simulate the main feature of the SOI responses to the ENSO-related SST variability in comparison with that in the reanalysis datasets, with the responses in the CMIP models exhibiting a larger diversity due to the complicated atmosphere-ocean interactions in these coupled models.

The zonal mass stream function responses in each AMIP5/6 model (Fig. 4a) are comparatively weaker than those in the reanalyses, but with a clear diversity between different models. The responses in one-third of the AMIP5/6 models (16 out of 45; ACCESS1-0, BCC-CSM1-1, CMCC-CM, EC-ERATH, FGOALS-g2, FGOALS-s2, HadGEM2-A, IPSL-CM5A-MR, MPIESM-LR, MPI-ESM-MR, BCCESM1, CAMS-CESM1-0, FGOALS-g3, MIROC6, MRI-ESM2-0, NESM3) are within the range of \pm 1 standard deviation (gray shading) of the responses in the reanalysis datasets. About twothirds of AMIP5/6 models significantly underestimate the responses by capturing $\sim 40 \%-75 \%$ of that in the reanalyses. In CMIP5/6 models (Fig. $4 \mathrm{~b}$ ), the responses in $10 \%$ models ( 6 out of 63, CMCC-CM, CMCC-CMS, GFDLESM2G, MPI-ESM-MR, MRI-CGCM3, MRI-ESM1) are overestimated compared to that of the reanalyses. The responses in 10 models (CSIRO-Mk3-6-0, FGOALSg2, GFDL-CM2p1, IPSL-CM5B-LR, MPI-ESM-LR, NorESM1-M, BCC-ESM1, GFDL-ESM4, MIROC6, MRI-ESM2-0) are within the range of \pm 1 standard deviation, while the responses in the other 47 CMIP5/6 models (about three-quarters of the total CMIP models) are underestimated compared to that in the reanalysis data. The above results indicate that in most of the AMIP5/6 and CMIP5/6 models, the WC responses to the ENSOrelated SST forcing are significantly underestimated. Only one-third (in AMIP) and one-fourth (in CMIP) of these models can well simulate the magnitude of the WC responses in comparison to that in the reanalysis datasets.

In the six reanalysis datasets, the response of mass stream function in ERA-Interim is comparable with others (Fig. 4). However, the SOI responses in ERA-Interim

\footnotetext{
(See figure on next page.)

Fig. 2 Zonal mass stream function regressed onto the Niño3.4 SST index during boreal winter $\left(10^{9} \mathrm{kgs}^{-1}{ }^{\circ} \mathrm{C}^{-1}\right)$. Color-mapping shows the regression coefficients of the zonal mass stream function in a reanalysis datasets, b AMIP5 models, c AMIP6 models, d CMIP5 models and e CMIP6 models. Gray dotted areas in a-e indicate that regression coefficients are significant at the $95 \%$ confidence level. $\mathbf{f}$ The quantification of the mass stream function responses to the ENSO-related SST forcing in different datasets. The white lines show the regression coefficients, and the ranges of the bars indicate the $95 \%$ confidence interval of these regression results with Student's $t$ test. $\mathbf{g}$ Is the box-whisker plots to indicate the spread of the reanalysis and model representation. On each box, the central line is the median, and the bottom and top edges of the box is the 25th and 75th percentiles, respectively. The whiskers extend to the most extreme data points not considered outliers. The' + ' symbol is the outliers in reanalyses or models
} 

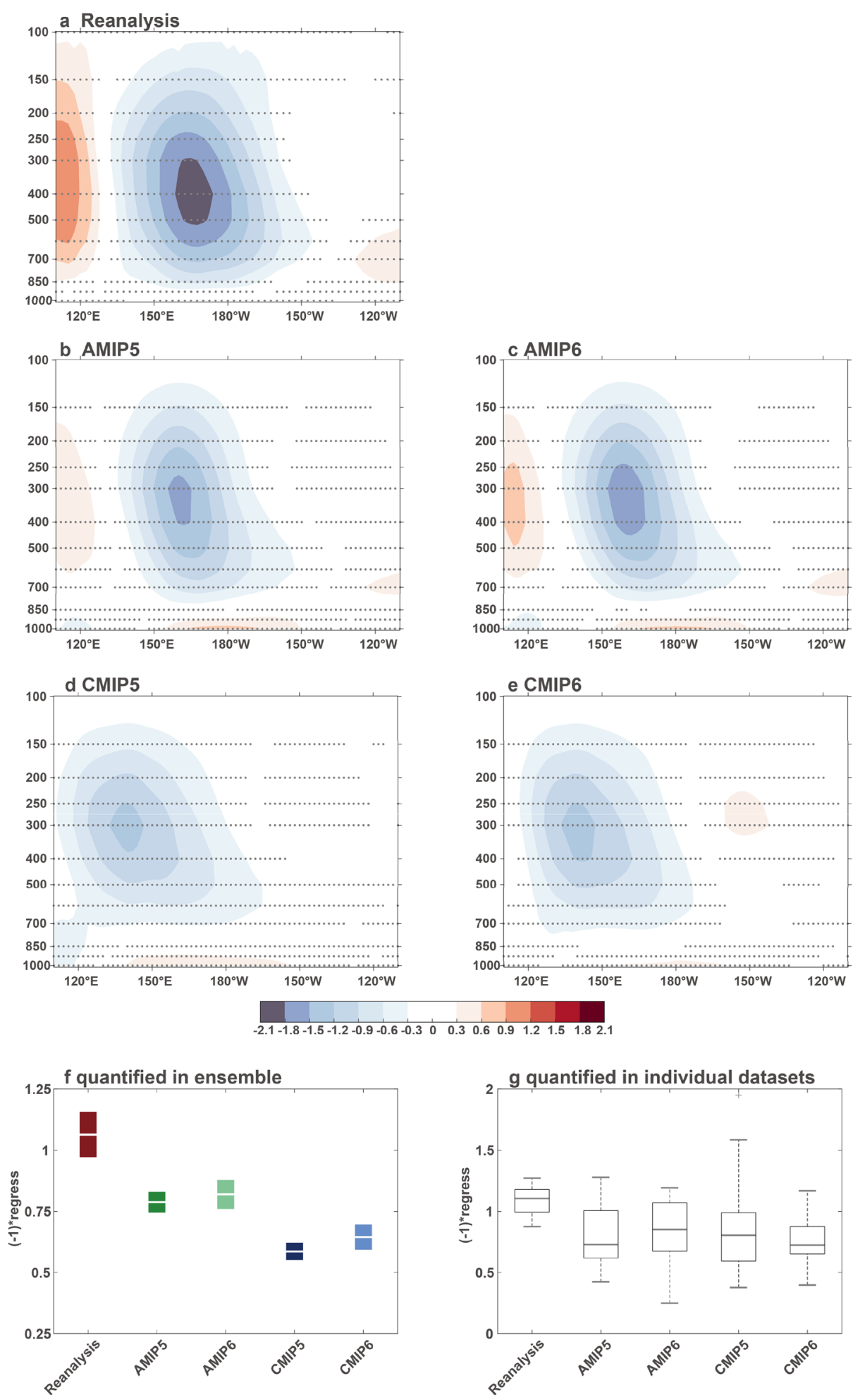

(Fig. 4) are much weaker than that in all other five reanalysis datasets. We further estimate the SLP responses over the eastern Pacific $\left(5^{\circ} \mathrm{S}-5^{\circ} \mathrm{N}, 80^{\circ} \mathrm{E}-160^{\circ} \mathrm{E}\right)$ and the western Pacific $\left(5^{\circ} \mathrm{S}-5^{\circ} \mathrm{N}, 160^{\circ} \mathrm{W}-80^{\circ} \mathrm{W}\right)$ in six individual reanalyses datasets. Results show that SLP responses in ERA-Interim are the weakest over both the eastern 

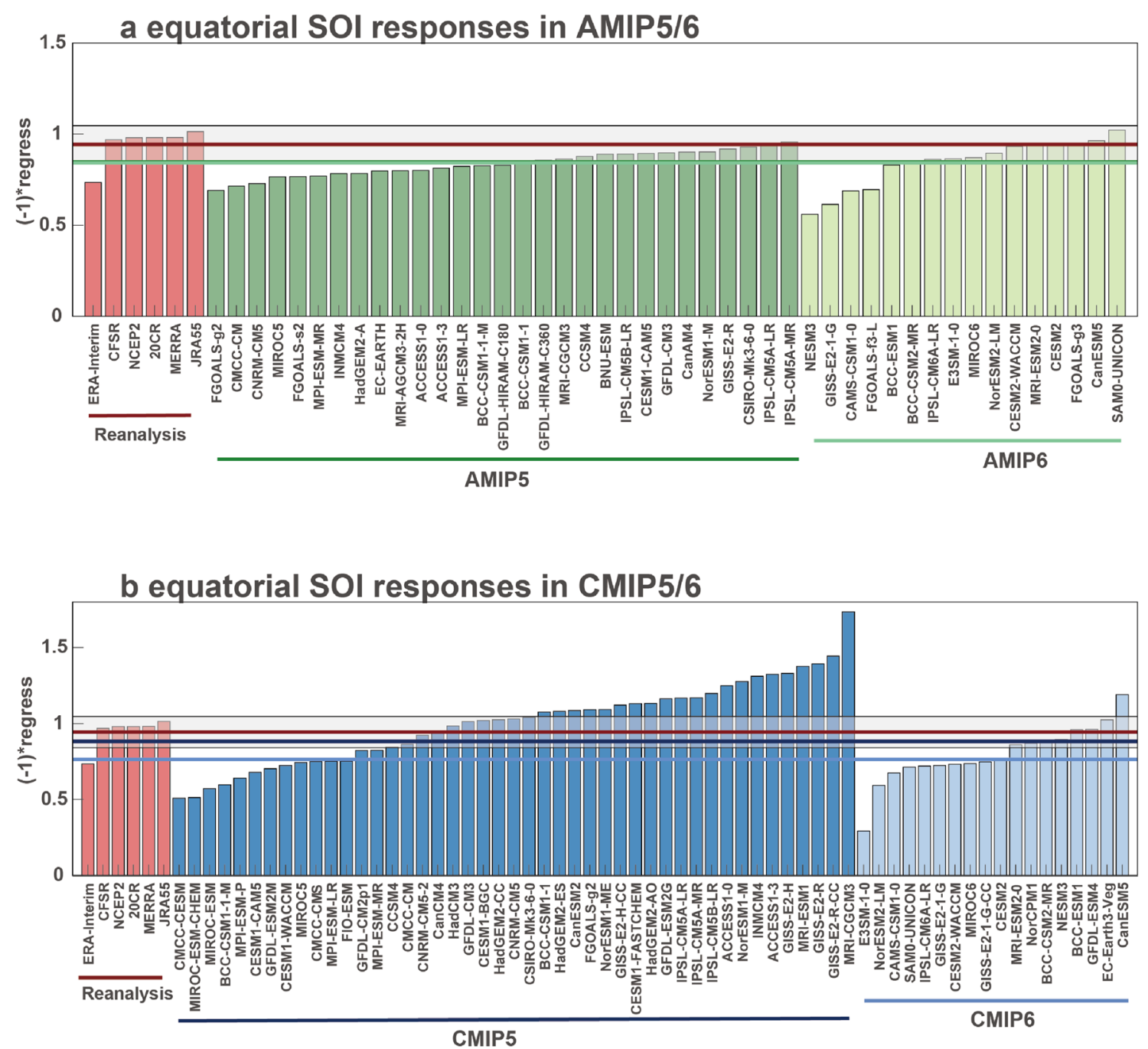

Fig. 3 Quantification of regression of SLP onto Niño3.4 SST index in each reanalysis and model $\left(\mathrm{hPa}^{-1}{ }^{\circ} \mathrm{C}^{-1}\right)$. a The regression results of SOI in AMIP5/6 models. $\mathbf{b}$ shows the results in CMIP5/6 models. Bars represent the regression coefficients of the SOI onto the Niño 3.4 SST index in each individual reanalysis (red bar) and model (deep green bars represent AMIP5 models; light green bars represent AMIP6 models; deep blue bars represent CMIP5 models; light blue bars represent CMIP6 models). Red, green and blue lines show the regression results of the multi-reanalysis ensemble and the multi-model ensemble, respectively. The gray shading indicates \pm 1 standard deviation of the responses in the reanalyses

and the western Pacific (Fig. S1). It is impressive that the SLP gradient (or the SOI) in ERA-Interim is less sensitive to the ENSO-related SST variability than that in the other reanalyses. The physical processes and mechanisms behind this diversity require further investigation.

In all individual models, the SLP index is positively related to stream function index. And it is the same for SLP responses and stream function responses (Additional file 1: Fig. S6). There is a consistency between each other. Above all, by comparing the responses of SOI and stream function in each individual model, we reveal that both the AMIP5/6 and CMIP5/6 models have strong diversity in reproducing the responses of the WC to the ENSO-related SST anomalies. In particular, the stream function responses to the ENSO-related SST variability in most of AMIP and CMIP models are weaker than that in the reanalyses. The AMIP5/6 models are directly forced by the observed SST variability, which do not involve the feedback from the atmosphere to the ocean (Gates et al. 1999). The weaker responses in AMIP5/6 models imply that some physical processes in the atmosphere may not be very well simulated. Considering that the tropical convective precipitation plays an important role in mediating the impacts of SST forcing on the large-scale tropical atmospheric circulation (Deser et al. 2010; Huang and Xie 2015), we further evaluate 



Fig. 4 Same as Fig. 4, but for the regression coefficients of zonal mass stream function $\left(10^{9} \mathrm{kgs}^{-1}{ }^{\circ} \mathrm{C}^{-1}\right)$. a The regression results of mass stream function in AMIP5/6 models. b The results in CMIP5/6 models. In most atmospheric and couple models, the responses of Walker circulation stream function are underestimated compared to those in the reanalysis datasets

the precipitation responses to the regional SST forcing in the reanalysis datasets and the AMIP/CMIP models. Figure 5a shows that the temperature gradient over the tropical Pacific Ocean associated with the ENSO events causes strong precipitation responses over both the west Pacific warm pool region (the black box in Fig. $5 \mathrm{a}, \mathrm{b}, 10^{\circ}$ $\left.\mathrm{S}-10^{\circ} \mathrm{N}, 95^{\circ} \mathrm{E}-145^{\circ} \mathrm{E}\right)$ and the equatorial central-eastern Pacific (the black box in Fig. $5 \mathrm{a}, \mathrm{b}, 5^{\circ} \mathrm{S}-5^{\circ} \mathrm{N}, 165^{\circ}$ $\left.\mathrm{E}-135^{\circ} \mathrm{W}\right)$. In response to the Niño3.4 SST warming, the precipitation over the warm pool region are weakened, whereas that over the equatorial central-eastern Pacific is intensified, both favoring a weakened Pacific WC. Positive precipitation responses appear in a warm SST region in all datasets although the magnitudes of responses are different. The precipitation responses over the warm pool region in AMIP5/6 (Fig. 5c, d) models are relatively weaker than that in GPCP (Fig. 5a), while the CMIP5/6 responses over both the warm pool region and the central-eastern tropical Pacific (Fig. 5e, f) are weaker.

We further quantify the precipitation responses to the ENSO-related SST forcing in the reanalysis datasets and the AMIP/CMIP models by calculating the difference of the precipitation responses between the warm pool region and the central-eastern Pacific. The results suggest that the AMIP5/6 and CMIP5/6 models only capture $\sim 80 \%$ and $70 \%$ of the precipitation responses compared to that in GPCP (Fig. 5g, h), respectively. There is a significant correlation between the $\mathrm{WC}$ responses and precipitation responses in individual reanalysis and model datasets (Additional file 1: Fig. S7). These results 

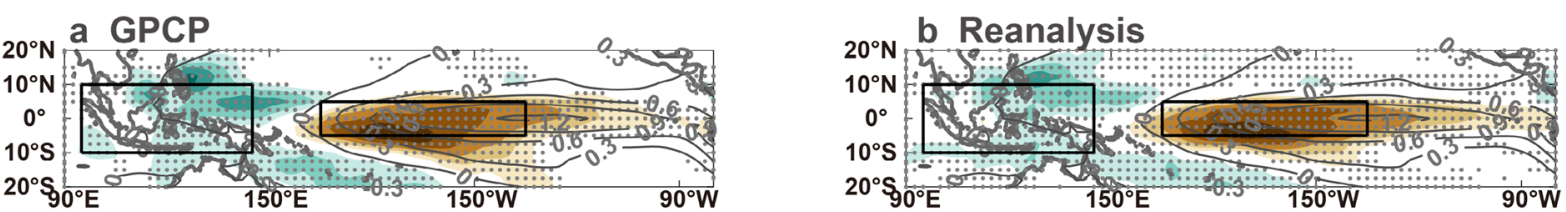

C AMIP5

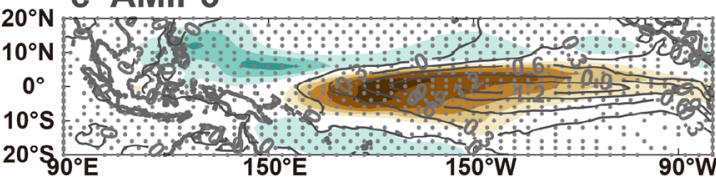

d AMIP6

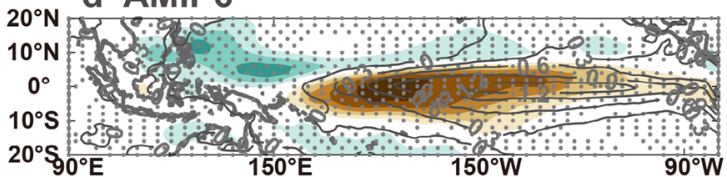

e CMIP5

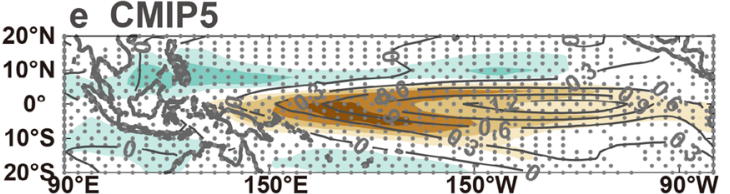

f CMIP6

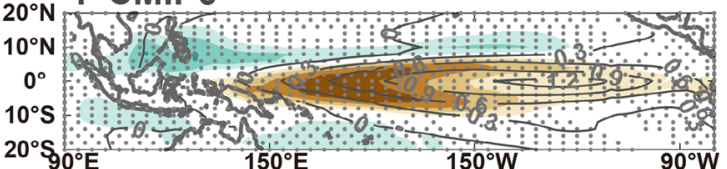

$\begin{array}{llllllllllllll}-3.6 & -3 & -2.4 & -1.8 & -1.2 & -0.6 & 0 & 0.6 & 1.2 & 1.8 & 2.4 & 3 & 3.6\end{array}$
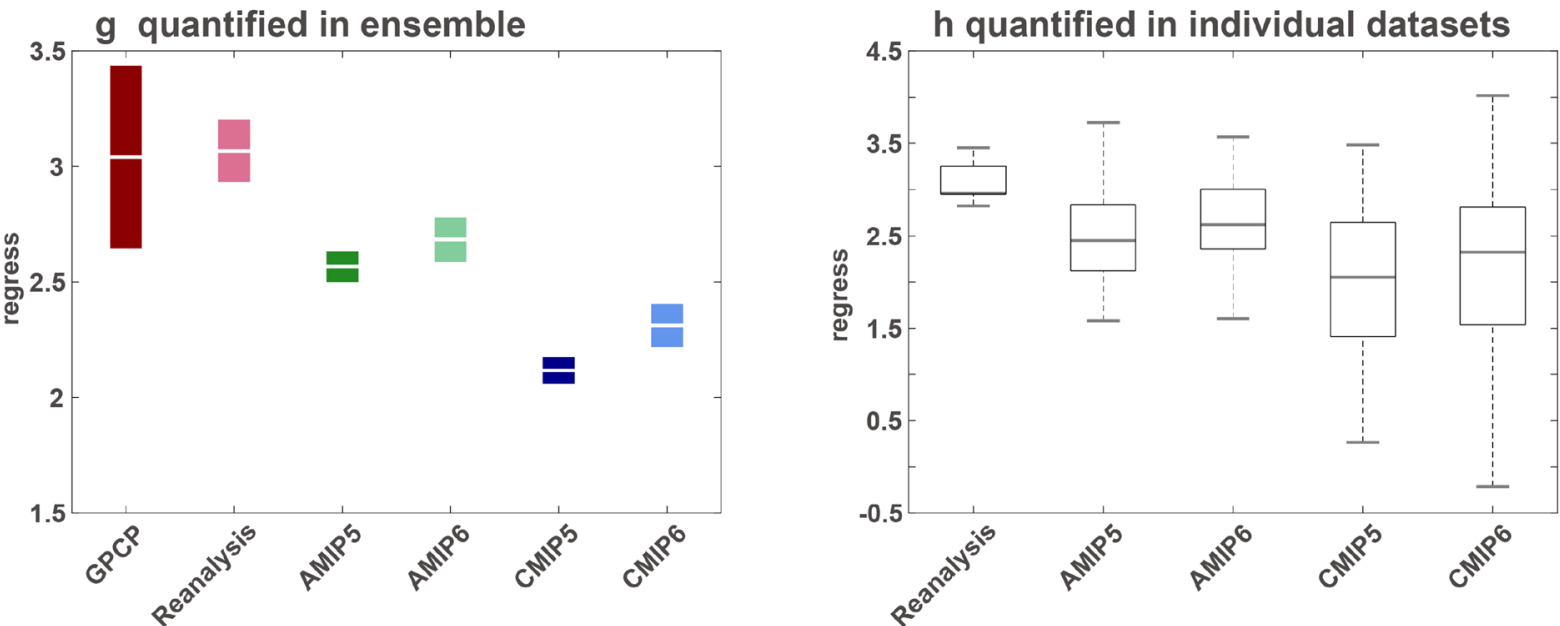

Fig. 5 Tropical precipitation regressed onto Niño3.4 SST index during boreal winter $\left(\mathrm{mm}^{-1} \mathrm{~d}^{-1}{ }^{\circ} \mathrm{C}^{-1}\right)$. Color-mapping and contour show the regression coefficients of precipitation and SST onto Niño 3.4 index in a GPCP, b reanalysis datasets, c AMIP5 models, d AMIP6 models, e CMIP5 models and $\mathbf{f}$ CMIP6 models. $\mathbf{g}$ That regression coefficients of the precipitation gradient (defined as the difference of the spatial-mean precipitation between the "cold tongue" region $5^{\circ} \mathrm{S}-5^{\circ} \mathrm{N}, 165^{\circ} \mathrm{E}-135^{\circ} \mathrm{W}$ and the "warm pool" region $10^{\circ} \mathrm{S}-10^{\circ} \mathrm{N}, 95^{\circ} \mathrm{E}-145^{\circ} \mathrm{E}$. These two regions are marked as black boxes in Fig. 5 a onto the Niño3.4 SST index in reanalyses and AMIP/CMIP models. The white lines show the regression coefficients, and the ranges of the bars indicate the $95 \%$ confidence interval of these regression results with Student's t test. Panel $\mathrm{h}$ is the box-whisker plots to indicate the spread of the reanalysis and model representation

indicate that the underestimation of the Pacific WC responses to the ENSO-related SST forcing could be associated with the underestimation of the precipitation responses over both the western Pacific warm pool and the central-eastern equatorial Pacific. This has also been demonstrated in the previous study (Bayr et al.
2020). Mean state of atmospheric convection controls the strength of ENSO atmospheric feedbacks. The biases in the precipitation responses have been shown in previous studies (Birch et al. 2015; Neale et al. 2013) to be further attributed to the biases in the parameterization schemes in the present atmospheric models. 


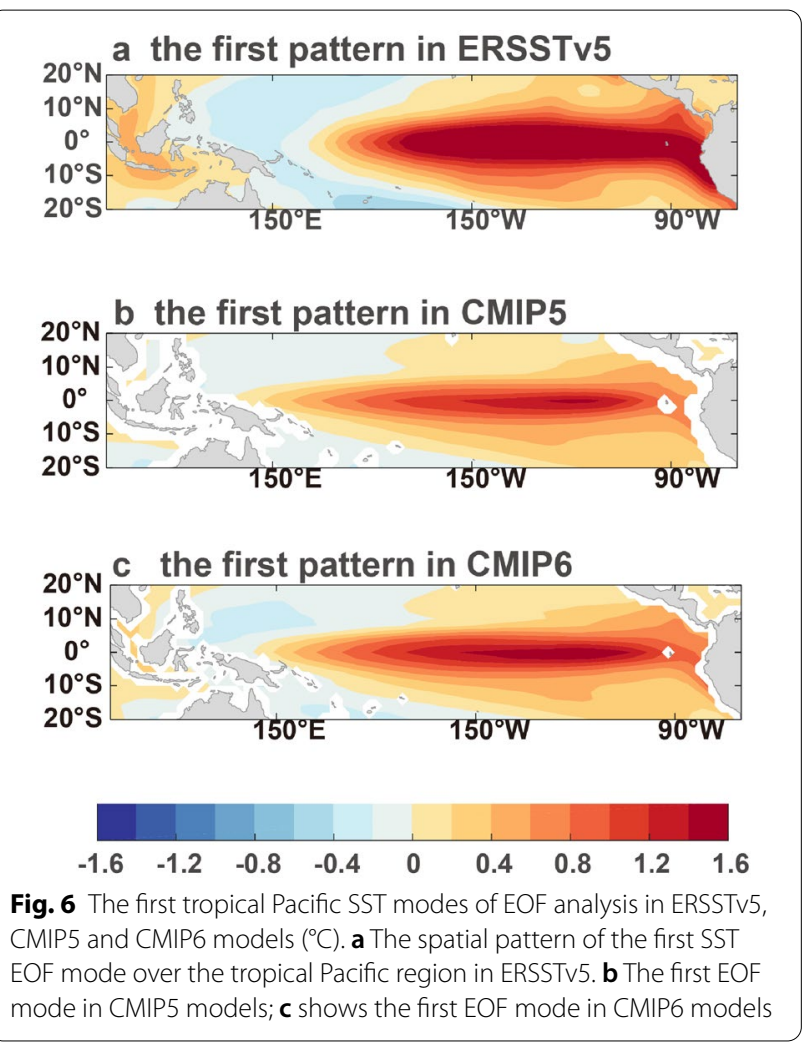

In CMIP models, the biases in the simulated ENSOrelated tropical SST pattern could also be a potential factor, which may contribute to the underestimation of the WC responses. AMIP models are forced with observed SST and only reflect atmospheric responses. However, CMIP models consist of the coupled atmosphere-ocean system. The intrinsic error existing in CMIP SST could cause biases in responses. Previous studies indicated that the CMIP models may not very well simulate the ENSO-related SST patterns (Cai et al. 2018, 2019; Li and Xie 2012). We thus perform EOF analysis using monthly SST anomalies in CMIP5 and CMIP6 models (Fig. 6b, c) and compare the first EOF mode (which is considered to be the ENSO-related SST mode) with that in the observation (Fig. 6a). The warm SST anomalies over the equatorial central-eastern Pacific in the coupled models show a clear westward extension compared to that in the observations, while the SST anomalies over the Western Pacific in the coupled models are much weaker than that in the observations. These more weakly and broadly extended SST patterns in the coupled models may potentially contribute to the weakened responses of the precipitation and the large-scale atmospheric circulation. We also display a scatter plot of ENSO-related SSTA and zonal mass stream function anomalies in CMIP5 and CMIP6 models (Additional file 1: Fig. S8). There is a negative correlation between ENSO SSTA and the WC in coupled models. These results indicate that ENSO SSTA could potentially influence the anomalies of WC and further related to weak atmospheric responses in CMIP5/6 models. In addition, the biases in the shortwave cloud radiative feedback (Chen et al. 2013) and the notorious double-ITCZ problem (Zhang et al. 2015) may also potentially contribute to these biases in the atmospheric circulation responses.

\section{Summary and discussion}

The WC is an important component in the tropical atmosphere-ocean interaction, which is measured by surface wind, SLP and zonal mass stream function. Recent studies indicated that the atmospheric responses, in particular, the surface wind responses to the ENSOrelated SST variability is underestimated in both AMIP and CMIP models (Bayr et al. 2020; Hayashi et al. 2020; Planton et al. 2020). However, the responses of the SLP and the WC stream function are not investigated. In this study, we use six reanalysis datasets, 45 AMIP5/6 models and 63 CMIP5/6 models to evaluate the simulated WC responses (involving the responses of SLP and zonal mass stream function) to ENSO-related SST anomalies in the state-of-the-art atmospheric and coupled models. We found that the ENSO-related SLP responses are reasonable in AMIP and CMIP models compared to that in reanalyses. However, the responses of the WC stream function to the Niño3.4 SST anomalies in boreal winter are underestimated in most of these AMIP and CMIP models, with a clear diversity between different models. The zonal mass stream function in AMIP5/6 and CMIP5/6 models in response to the Niño 3.4 SST anomalies only capture about $75 \%$ and $58 \%$ of that in reanalyses. This low bias in most individual AMIP5/6 and CMIP5/6 models is prominent.

The underestimation of WC mass stream function responses in AMIP5/6 and CMIP5/6 investigated in this study is consistent with previous studies (Bayr et al. 2020; Hayashi et al. 2020; Planton et al. 2020), which revealed the low bias in the ENSO-related surface wind feedback. Mass stream function and surface wind are both important measures of the WC. Our results of the WC stream functions well agree with the previous studies (Bayr et al. 2020; Hayashi et al. 2020; Planton et al. 2020), highlighting the importance that the ENSO-related atmospheric feedback in the atmospheric and climate models needs to be further improved.

However, in contrast to the low biases of the ENSOrelate WC and surface wind responses, the SLP (or the SOI) responses to the equatorial Pacific SST variability is well simulated in most of atmospheric and coupled models, as revealed in this study. Similarly, the 
ENSO-related SLP (SOI) response in ERA-interim is much weaker than that of the other reanalyses, while the WC responses in ERA-interim is comparable with that in other reanalyses. The SLP gradient is an important proxy of the Walker circulation, and represents the Southern Oscillation. The difference in the WC responses and the SLP responses highlights the complexity of the ENSO-related biases, which requires further investigation.

Further analysis indicates that the bias in AMIP5/6 models may be attributed to the underestimation of the precipitation in response to the ENSO-related SST variability, especially precipitation responses over the warm pool region, whereas the westwards extension of central-eastern equatorial Pacific SST anomaly in the CMIP models may further weaken the circulation responses to the ENSO forcing.

The WC plays an important role in mediating the interactions between the ocean and atmosphere, and by connecting the impacts of ENSO events to the global climate variability (Bjerknes 1969; Li et al. 2016; Philander 1990). Our results indicate that the responses of the WC to ENSO-related SST variability are commonly underestimated in most of the current widely used atmospheric and coupled models. This bias may substantially influence the capability of these atmospheric and coupled models in reproducing the Bjerknes feedback, a key process of the tropical atmosphere-ocean interaction. This underestimation may further result in the deficiencies in simulating and predicting ENSO events using these models. In addition, these biases could affect the teleconnection patterns and further modulate the impacts of ENSO events on global climate in the earth system models. Our study suggests that we need to pay more attention to removing the biases of the fundamental ocean-atmospheric interaction processes in the atmospheric and climate system models.

\section{Abbreviations}

AMIP5/6: The Atmospheric Model Intercomparison Project phase 5 and 6; CMIP5/6: The Coupled Model Intercomparison Project phase 5 and 6; ENSO: El Niño-Southern Oscillation; SLP: Sea level pressure; SOI: Southern oscillation index; SST: Sea surface temperature; WC: Walker circulation.

\section{Supplementary Information}

The online version contains supplementary material available at https://doi. org/10.1186/s40562-021-00186-8.

Additional file 1.Table S1. 1 Details of 45 CMIP5 models used in the study. Table S1. 2 Details of 19 CMIP6 models used in the study. Table S1. 3 Details of 29 AMIP5 models used in the study. Table S1. 4 Details of 16 AMIP6 models used in the study. Figure S1. Sea level pressure (SLP) regressed onto the Niño3.4 SST index during the period from 1979-2005 in each individual reanalysis and AMIP5/6 model. Figure S2. Same as figure S1 but in each individual CMIP5/6 model. Figure S3. Zonal mass stream function regressed onto the Niño3.4 SST index during the period from 1979-2005 in each individual reanalysis and AMIP5/6 model. Figure S4. Same as figure S3 but in each individual CMIP5/6 model. Figure S5. Taylor diagram for showing the statistics of responses in reanalyses and models. The relative mean squared difference and the spatial pattern correlation between model and six reanalysis-ensembles. Different color dots represent different reanalyses and models. Panel a shows the performance of Sea Level Pressure responses; panel $\mathbf{b}$ shows the performance of zonal mass stream function responses. Figure S6. The relationship between $\mathrm{SOI}$ anomalies and the max of zonal mass stream function anomalies and between $\mathrm{SOI}$ responses and the max of zonal mass stream function responses. Figure S7. The relationship between the max of zonal mass stream function responses and precipitation responses in individual models and reanalyses. Figure $\mathbf{S 8}$. The relationship between ENSO-related SST anomalies and the max of zonal mass stream function anomalies in individual a CMIP5 models and b CMIP6 models.

\section{Acknowledgements}

Xin-Yue Wang and Xichen Li were supported by the National Key Research and Development Program of China (Grant No. 2016YFA0601802), the Key Research Program of Frontier Sciences, CAS (Grant No. ZDBS-LY-DQC010) and the National Natural Science Foundation of China (Grant No. 41676190 and No. 41976193). Chueh-Hsin Chang was funded by the National Research Foundation of Korea (Grant No. NRF-2018R1A6A1A08025520).

\section{Authors' contributions}

XYW analyzed the datasets and wrote the manuscript. XL initiated the idea of this study and revised manuscript. Other authors contributed to the data downloads. All authors read and approved the final manuscript.

\section{Funding}

Xin-Yue Wang and Xichen Li were funded by the National Key Research and Development Program of China (Grant No. 2016YFA0601802), the Key Research Program of Frontier Sciences, CAS (Grant No. ZDBS-LY-DQC010) and the National Natural Science Foundation of China (Grant Nos. 41676190 and 41976193). Chueh-Hsin Chang was funded by the National Research Foundation of Korea (Grant No. NRF-2018R1A6A1A08025520).

\section{Availability of data and materials}

The observed and reanalysis datasets used in this study were downloaded from National Center for Atmospheric Research (https://rda.ucar.edu/). The Modern-Era Retrospective analysis for Research (MERRA) are from National Aeronautics and Space Administration (https://disc.gsfc.nasa.gov/datasets? page $=1 \&$ keywords $=$ merra). The Niño34 SST index is download from Climate Prediction Center (https://www.cpc.ncep.noaa.gov/products/analysis_ monitoring/ensostuff/detrend.nino34.ascii.txt). CMIP5/6 and AMIP5/6 model datasets are download from World Climate Research Programme (https://esgfnode.IInl.gov/search/).

\section{Declarations}

\section{Competing interests}

The authors declare that they have no competing interests.

\section{Author details}

${ }^{1}$ Institute of Atmospheric Physics, Chinese Academy of Sciences, Beijing, China. ${ }^{2}$ University of Chinese Academy of Sciences, Beijing, China. ${ }^{3}$ Center for Climate Change Prediction Research, Ewha Womans University, Seoul, South Korea. ${ }^{4}$ Atmospheric Oceanic Sciences Program, Princeton University, Princeton, NJ 08540, USA. ${ }^{5}$ NOAA Geophysical Fluid Dynamics Laboratory, Princeton, NJ 08540, USA. ${ }^{6}$ State Key Laboratory of Satellite Ocean Environment Dynamics, Second Institute of Oceanography, Ministry of Natural Resources, Hangzhou, China.

Received: 10 October 2020 Accepted: 5 April 2021

Published online: 19 April 2021 


\section{References}

Bayr T, Dommenget D, Latif M (2020) Walker circulation controls ENSO atmospheric feedbacks in uncoupled and coupled climate model simulations. Clim Dyn 54:2831-2846. https://doi.org/10.1007/s00382-020-05152-2

Bellenger H, Guilyardi E, Leloup J, Lengaigne M, Vialard J (2014) ENSO representation in climate models: from CMIP3 to CMIP5. Clim Dyn 42(7-8):1999-2018. https://doi.org/10.1007/s00382-013-1783-z

Birch CE, Roberts MJ, Garcia-Carreras L, Ackerley D, Reeder MJ, Lock AP, Schiemann R (2015) Sea-breeze dynamics and convection initiation: the influence of convective parameterization in weather and climate model biases. J Clim 28(20):8093-8108. https://doi.org/10.1175/ JCLI-D-14-00850.1

Bjerknes J (1969) Atmospheric teleconnections from the equatorial Pacific. Mon Weather Rev 97(3):163-172. https://doi.org/10.1175/15200493(1969)097\%3c0163:ATFTEP\%3e2.3.CO;2

Cai W, Wang G, Dewitte B, Wu L, Santoso A, Takahashi K, Yang Y, Carreric A, McPhaden MJ (2018) Increased variability of eastern Pacific El Niño under greenhouse warming. Nature 564(7735):201-206. https://doi.org/10. 1038/s41586-018-0776-9

Cai W, Wu L, Lengaigne M, Li T, McGregor S, Kug J-S, Yu J-Y, Stuecker MF, Santoso A, Li X, Ham Y-G, Chikamoto Y, Ng B, McPhaden MJ, Du Y, Dommenget D, Jia F, Kajtar JB, Keenlyside N, Lin X, Luo J-J, Martin-Rey M, Ruprich-Robert Y, Wang G, Xie S-P, Yang Y, Kang SM, Choi J-Y, Gan B, Kim G-I, Kim C-E, Kim S, Kim J-H, Chang P (2019) Pantropical climate interactions. Science 363(6430):4236. https://doi.org/10.1126/science.aav4236

Chen L, Yu Y, Sun D-Z (2013) Cloud and water vapor feedbacks to the El Niño warming: are they still biased in CMIP5 models? J Clim 26(14):4947-4961. https://doi.org/10.1175/jcli-d-12-00575.1

Compo GP, Whitaker JS, Sardeshmukh PD, Matsui N, Allan RJ, Yin X, Gleason BE Jr, Vose RS, Rutledge G, Bessemoulin P, Broennimann S, Brunet M, Crouthamel RI, Grant AN, Groisman PY, Jones PD, Kruk MC, Kruger AC, Marshall GJ, Maugeri M, Mok HY, Nordli O, Ross TF, Trigo RM, Wang XL, Woodruff SD, Worley SJ (2011) The twentieth century reanalysis project. Q J R Meteorol Soc 137(654):1-28. https://doi.org/10.1002/qj.776

Davey M, Huddleston M, Sperber K, Braconnot P, Bryan F, Chen D, Colman R, Cooper C, Cubasch U, Delecluse P (2002) STOIC: a study of coupled model climatology and variability in tropical ocean regions. Clim Dyn 18(5):403-420. https://doi.org/10.1007/s00382-001-0188-6

Dee DP, Uppala SM, Simmons AJ, Berrisford P, Poli P, Kobayashi S, Andrae U, Balmaseda MA, Balsamo G, Bauer P, Bechtold P, Beljaars ACM, van de Berg L, Bidlot J, Bormann N, Delsol C, Dragani R, Fuentes M, Geer AJ, Haimberger L, Healy SB, Hersbach H, Holm EV, Isaksen L, Kallberg P, Koehler M, Matricardi M, McNally AP, Monge-Sanz BM, Morcrette JJ, Park BK, Peubey C, de Rosnay P, Tavolato C, Thepaut JN, Vitart F (2011) The ERA-Interim reanalysis: configuration and performance of the data assimilation system. Q J R Meteorol Soc 137(656):553-597. https://doi.org/10.1002/qj.828

Deser C, Phillips AS, Alexander MA (2010) Twentieth century tropical sea surface temperature trends revisited. Geophys Res Lett. https://doi.org/ 10.1029/2010gl043321

DiNezio PN, Vecchi GA, Clement AC (2013) Detectability of changes in the walker circulation in response to global warming. J Clim 26(12):40384048. https://doi.org/10.1175/jcli-d-12-00531.1

Gates WL, Boyle JS, Covey C, Dease CG, Doutriaux CM, Drach RS, Fiorino M, Gleckler PJ, Hnilo JJ, Marlais SM, Phillips TJ, Potter GL, Santer BD, Sperber KR, Taylor KE, Williams DN (1999) An overview of the results of the Atmospheric Model Intercomparison Project (AMIP I). Bull Am Meteor Soc 80(1):29-55. https://doi.org/10.1175/1520-0477(1999)080\%3c0029: Aootro\%3e2.0.Co;2

Hayashi M, Jin F-F, Stuecker MF (2020) Dynamics for El Niño-La Niña asymmetry constrain equatorial-Pacific warming pattern. Nat Commun 11(1):1-10. https://doi.org/10.1038/s41467-020-17983-y

Huang P, Xie S-P (2015) Mechanisms of change in ENSO-induced tropical Pacific rainfall variability in a warming climate. Nat Geosci 8(12):922-926. https://doi.org/10.1038/ngeo2571

Huang B, Thorne PW, Banzon VF, Boyer T, Chepurin G, Lawrimore JH, Menne MJ, Smith TM, Vose RS, Zhang H-M (2017) Extended reconstructed sea surface temperature, Version 5 (ERSSTV5): upgrades, validations, and intercomparisons. J Clim 30(20):8179-8205. https://doi.org/10.1175/ jcli-d-16-0836. 1
Huffman GJ, Adler RF, Bolvin DT, Gu G (2009) Improving the global precipitation record: GPCP Version 21. Geophys Res Lett 36:12. https://doi.org/10. 1029/2009GL040000

Kanamitsu M, Ebisuzaki W, Woollen J, Yang SK, Hnilo JJ, Fiorino M, Potter GL (2002) NCEP-DOE AMIP-II reanalysis (R-2). Bull Am Meteorol Soc 83(11): 1631-1643 https://doi.org/10.1175/bams-83-11-1631

Kobayashi S, Ota Y, Harada Y, Ebita A, Moriya M, Onoda H, Onogi K, Kamahori H, Kobayashi C, Endo H, Miyaoka K, Takahashi K (2015) The JRA-55 reanalysis: general specifications and basic characteristics. J Meteorol Soc Jpn 93(1):5-48. https://doi.org/10.2151/jmsj.2015-001

Kociuba G, Power SB (2015) Inability of CMIP5 models to simulate recent strengthening of the walker circulation: implications for projections. J Clim 28(1):20-35. https://doi.org/10.1175/jcli-d-13-00752.1

Lau K, Yang S (2003) Walker circulation. Encycloped Atmos Sci. https://doi.org/ 10.1016/BO-12-227090-8/00450-4

Li G, Xie SP (2012) Origins of tropical-wide SST biases in CMIP multi-model ensembles. Geophys Res Lett 39(22): L22703 https://doi.org/10.1029/ 2012GL053777

Li X, Xie S-P, Gille ST, Yoo C (2016) Atlantic-induced pan-tropical climate change over the past three decades. Nat Clim Chang 6(3):275-279. https://doi.org/10.1038/nclimate2840

Ma S, Zhou T (2016) Robust strengthening and westward shift of the tropical pacific walker circulation during 1979-2012: a comparison of 7 sets of reanalysis data and 26 CMIP5 models. J Clim 29(9):3097-3118. https://doi.org/10.1175/jcli-d-15-0398.1

Mechoso CR, Robertson AW, Barth N, Davey MK, Delecluse P, Gent PR, Ineson S, Kirtman B, Latif M, Letreut H, Nagai T, Neelin JD, Philander SGH, Polcher J, Schopf PS, Stockdale T, Suarez MJ, Terray L, Thual O, Tribbia JJ (1995) The seasonal cycle over the tropical pacific in coupled ocean-atmosphere general-circulation models. Mon Weather Rev 123(9):2825-2838. https://doi.org/10.1175/1520-0493(1995)123\% 3c2825:Tscott\%3e2.0.Co;2

Neale RB, Richter J, Park S, Lauritzen PH, Vavrus SJ, Rasch PJ, Zhang M (2013) The mean climate of the community atmosphere model (CAM4) in forced SST and fully coupled experiments. J Clim 26(14):5150-5168. https://doi.org/10.1175/jcli-d-12-00236.1

Philander SG (1990) El Niño, La Niña, and the southern oscillation. Springer, London, p 289

Planton YY, Guilyardi E, Wittenberg AT, Lee J, Gleckler PJ, Bayr T, McGregor S, McPhaden MJ, Power S, Roehrig R (2020) Evaluating climate models with the CLIVAR 2020 ENSO metrics package. Bull Am Meteorol Soc 24:1-57. https://doi.org/10.1175/BAMS-D-19-0337.1

Power S, Casey T, Folland C, Colman A, Mehta V (1999) Inter-decadal modulation of the impact of ENSO on Australia. Clim Dyn 15(5):319-324. https://doi.org/10.1007/s003820050284

Rasmusson EM, Carpenter TH (1982) Variations in tropical sea surface temperature and surface wind fields associated with the Southern Oscillation/El Niño. Mon Weather Rev 110(5):354-384. https://doi.org/ 10.1175/1520-0493(1982)110\%3c0354:Vitsst\%3e2.0.Co;2

Rienecker MM, Suarez MJ, Gelaro R, Todling R, Bacmeister J, Liu E, Bosilovich MG, Schubert SD, Takacs L, Kim G-K, Bloom S, Chen J, Collins D, Conaty A, Da Silva A, Gu W, Joiner J, Koster RD, Lucchesi R, Molod A, Owens T, Pawson S, Pegion P, Redder CR, Reichle R, Robertson FR, Ruddick AG, Sienkiewicz M, Woollen J (2011) MERRA: NASA's modern-era retrospective analysis for research and applications. J Clim 24(14):3624-3648. https://doi.org/10.1175/jcli-d-11-00015.1

Saha S, Moorthi S, Pan H-L, Wu X, Wang J, Nadiga S, Tripp P, Kistler R, Woollen J, Behringer D, Liu H, Stokes D, Grumbine R, Gayno G, Wang J, Hou Y-T, Chuang H-Y, Juang H-MH, Sela J, Iredell M, Treadon R, Kleist D, Van Delst P, Keyser D, Derber J, Ek M, Meng J, Wei H, Yang R, Lord S, Van den Dool H, Kumar A, Wang W, Long C, Chelliah M, Xue Y, Huang B, Schemm J-K, Ebisuzaki W, Lin R, Xie P, Chen M, Zhou S, Higgins W, Zou C-Z, Liu Q Chen Y, Han Y, Cucurull L, Reynolds RW, Rutledge G, Goldberg M (2010) The NCEP climate forecast system reanalysis. Bull Am Meteor Soc 91(8):1015-1057. https://doi.org/10.1175/2010bams3001.1

Stocker TF, Qin D, Plattner G-K, Tignor M, Allen SK, Boschung J, Nauels A, Xia Y, Bex V, Midgley PM (2013) Climate change 2013: The physical science basis. Contribution of working group I to the fifth assessment report of the intergovernmental panel on climate change. Cambridge University Press, Cambridge, p 1535 
Tanaka HL, Ishizaki N, Kitoh A (2004) Trend and interannual variability of Walker, monsoon and Hadley circulations defined by velocity potential in the upper troposphere. Tellus A 56(3): 250-269 https://doi.org/10. 1111/j.1600-0870.2004.00049.x

Taylor KE, Stouffer RJ, Meehl GA (2012) An overview of CMIP5 and the experiment design. Bull Am Meteor Soc 93(4):485-498. https://doi.org/ 10.1175/bams-d-11-00094.1

Vecchi GA, Soden BJ (2007) Global warming and the weakening of the tropical circulation. Bull Am Meteor Soc 88(10):1529-1530. https://doi. org/10.1175/JCLI4258.1

Wang B, Liu J, Kim H-J, Webster PJ, Yim S-Y (2012) Recent change of the global monsoon precipitation (1979-2008). Clim Dyn 39(5):1123-1135. https://doi.org/10.1007/s00382-011-1266-Z

Wang C, Deser C, Yu J-Y, DiNezio P, Clement A (2016) El Niño and southern oscillation (ENSO): a review. In: Coral reefs of the eastern tropical Pacific. Berlin: Springer, pp 85-106. doi: https://doi.org/10.1007/ 978-94-017-7499-4_4

Yu B, Zwiers FW (2010) Changes in equatorial atmospheric zonal circulations in recent decades. Geophys Res Lett 37:L05701. https://doi.org/ $10.1029 / 2009 \mathrm{gl} 042071$
Yu B, Zwiers FW, Boer GJ, Ting MF (2012) Structure and variances of equatorial zonal circulation in a multimodel ensemble. Clim Dyn 39(910):2403-2419. https://doi.org/10.1007/s00382-012-1372-6

Zhang $L$ (2016) The roles of external forcing and natural variability in global warming hiatuses. Clim Dyn 47(9-10):3157-3169. https://doi.org/10. 1175/jcli-d-16-0349.1

Zhang W, Li J, Zhao X (2010) Sea surface temperature cooling mode in the Pacific cold tongue. J Geophys Res 115:C12042. https://doi.org/10.1029/ 2010JC006501

Zhang X, Liu H, Zhang M (2015) Double ITCZ in coupled ocean-atmosphere models: from CMIP3 to CMIP5. Geophys Res Lett 42(20):8651-8659. https://doi.org/10.1002/2015gl065973

\section{Publisher's Note}

Springer Nature remains neutral with regard to jurisdictional claims in published maps and institutional affiliations.

\section{Submit your manuscript to a SpringerOpen ${ }^{\circ}$ journal and benefit from:}

- Convenient online submission

- Rigorous peer review

- Open access: articles freely available online

- High visibility within the field

- Retaining the copyright to your article

Submit your next manuscript at $\boldsymbol{\nabla}$ springeropen.com 